\title{
Feasibility study of a new platform based on the Case-Based Reasoning principles to efficiently search and store voxel phantoms
}

\author{
J. HENRIET ${ }^{1}$, J. FARAH ${ }^{2}$, B. CHEBEL-MORELLO ${ }^{3}$, M. BOPP ${ }^{1}$, \\ D. BROGGIO ${ }^{2}$, L. MAKOVICKA ${ }^{1}$
}

(Manuscript received 25 August 2009, accepted 25 November 2009)

ABSTRACT In case of accidental exposure to radiation, it is necessary to establish as soon as possible a dosimetry report for each victim. In most cases, this report is based on medical images of the victim, enabling the construction of a personalized realistic numerical model, also called a voxel phantom. Unfortunately it is not always possible to perform the medical imaging of the victim since the technology may be unavailable or to avoid additional exposure to radiation. In such cases, the commonly used method is to represent the victim with a numerical model like the "Reference Man", a voxelized phantom representative of the average male individual. The treatment accuracy depends on the diagnosis precision and, consequently, on the similarity of the phantom and/to the victim. A precise dosimetry evaluation requires a personalised and realistic phantom whose biometric characteristics match the victim; such model is often unavailable. The Case-Based Reasoning (CBR) is a problem solving method for the conception of intelligent systems. It imitates the analysis, understanding and reconstruction of the human intelligence. The ReEPh project (Research of Equivalent Phantom) proposes to use the CBR principles to retrieve from a set of phantoms, the most adapted one to the irradiated victim. For this study, the ReEPh platform retrieves, stores and compares existing phantoms to a victim. A graphic interface enables the user to compare victim's characteristics to the ones of the most similar phantoms available in the database. This defines a similarity index presenting the equivalence between the victim and the suggested phantom. Moreover, a confidence index is also assessed to define the uncertainty implied by the RaPC choice procedure.

Keywords: Radiation protection / case-based reasoning / voxel phantoms

RÉSUMÉ Étude de faisabilité d'une plate-forme originale basée sur le raisonnement à partir de cas pour la recherche et le stockage de fantômes voxélisés.

En cas d'accident radiologique il est nécessaire d'établir, le plus rapidement possible, un bilan dosimétrique de chaque victime. Dans la plupart des cas, ces bilans sont basés sur des images médicales du corps humain, permettant ainsi de construire un modèle numérique de la victime appelé fantôme voxélisé. Malheureusement, il n'est pas toujours possible de réaliser l'imagerie médicale, le matériel n'étant pas immédiatement disponible ou pour éviter une exposition supplémentaire de la

\footnotetext{
Université de Franche-Comté, IRMA/ENISYS/FEMTO-ST, UMR 6174 CNRS, 4 place Tharradin, 25200 Montbéliard, France.

2 IRSN, LEDI/SDI/DPRH, BP-17, 92262 Fontenay-aux-Roses, France.

3 Université de Franche-Comté, COSMI/AS2M/FEMTO-ST, UMR 6174 CNRS, 24 rue Alain Savary, 25000 Besançon, France.
} 


\begin{abstract}
victime aux radiations. L'adaptation des traitements dépend directement de la rapidité et la précision du diagnostic, et par conséquent de la ressemblance du fantôme à la victime. Le raisonnement à partir de cas (RàPC) est une méthode de résolution de problèmes imitant le raisonnement humain. Le projet ReEPh (Research of Equivalent Phantom) repose sur les principes du RàPC pour retrouver, adapter et stocker les fantômes voxélisés les plus proches des victimes. Cette première version de la plate-forme intègre le stockage de nouveaux fantômes ainsi que la recherche des fantômes connus les plus proches des caractéristiques d'une victime en se basant sur le calcul de la similarité et d'un indice de confiance, certaines caractéristiques de la victime pouvant être ignorées.
\end{abstract}

\title{
1. Introduction
}

In the case of accidental exposure to radiation, it is necessary to establish as soon as possible a dosimetric report for each victim. In most cases, this report is based on available 3D voxel phantoms which are numerical models based on medical images (CT scan or RMI images). Examples of use of voxel phantom for dosimetric assessment following internal contamination are given by (de Carlan et al., 2003; Broggio et al., 2009), while examples of their use in the case of external exposure to radiation are given by (Clairand et al., 2008; Huet et al., 2009). However, a victim specific phantom is not always available. Indeed, a realistic and personalized voxel phantom construction is time consuming and requires delicate manual segmentation of the organs of interest when the medical images are available. This also requires particular skills and a minimal knowledge of the human anatomy to make the organs differentiation. In the case of an accidental urgent study, such time and effort are highly unlikely to be invested. Moreover, the medical images are avoided to prevent any additional exposure to radiation. Thus, existing models are used in such situations even if their characteristics may be far from the biometrical data of the victim. The dosimetry assessment accuracy, and resulting medical actions of decontamination, are highly dependent on the similarity of the phantom to the victim. The more the phantom resembles the biometrical data of the victim, the better the dosimetry assessment and thus the medical care and reaction. Hence, the actual work aims to assist the physician in choosing the best fitting phantom from the existing and available models.

The Case-Based Reasoning (CBR) is a problem solving method for the conception of intelligent systems. It imitates the analysis, understanding and reconstruction of the human intelligence. Moreover, it is first and foremost the opening of new possibilities of problem solving methods. This is why several disciplines like the Artificial Neural Network (ANN) or the CBR received a substantial boost in recent years (Makovicka et al., 2009). Nowadays it is more and more important to quickly find and retrieve the required information from very large databanks, libraries or any other source of information. 
The ReEPh project (Research of Equivalent Phantom) strikes a new path in the field of problem solving methods, for the particular radiation protection application, since it uses the CBR approach, until now exclusively (but widely) used in industrial maintenance, to realise the aspects mentioned above. The idea is now to use the CBR-approach to find the most similar phantom in a base of cases and then try to adapt this phantom to the characteristics of the victim.

First, this paper reviews a history of the different numerical phantoms and particularly the voxelized ones, their development methodology, purpose and use. Next, it describes the principles of CBR and presents the ReEPh platform with its different compounds. And finally it shows an example of the results obtained considering a given accidental situation and the use of the ReEPh application.

\section{A survey of voxelized phantoms}

Many studies and research groups have been working on numerical phantoms design and development. The ICRU report 48 (ICRU, 1992) distinguishes mathematical phantoms from voxelized ones.

Mathematical phantoms use simple geometric figures to describe the organs such as spheres, cones or ellipses. In this category, most of nowadays mathematical phantoms are based on the Snyder's phantom (Snyder et al., 1978). The Oak Ridge National Laboratory (ORNL) phantoms are an evolution of the Eckermann's one (Cristy and Eckermann, 1987). Male and female adult phantoms (Adam and Eva) of the HZM (Helmholtz Zentrum München) have been elaborated from the MIRD model (Kramer et al., 1982). Clairand (1999) also defined three male and three female phantoms with different dimensions. Whereas all these phantom models are Caucasian human being, Tanaka et al. elaborated an Asian one for Hiroshima survivors' dosimetry studies (Tanaka et al., 1979).

Due to the advances in computer technology, it is possible to create more complex figures representing realistic 3D organs. Hence, voxelized models were introduced to enable realistic anthropomorphic phantoms creation. Such models are elaborated using medical images like the Computed Tomography (CT scan) images or the Magnetic Resonance Images (MRI) ones. The HZM digitized a male, a female (Zankl et al., 1988) and two children models: one representing an eight weeks old subject called BABY, and the other one a seven years old subject called CHILD (Zankl et al., 1995). More phantoms were developed like the NORMAN one (for NORmal MAN) of the National Radiological Protection Board (Dimbylow, 1998), and the one of Zubal (Zubal et al., 1994). ADELAIDE (Caon et al., 1999), GOLEM (Zankl et al., 2001), developed by Zankl and Wittmann are also voxel phantoms, same for FAX (Kramer et al., 2003) and MAX 
(Kramer et al., 2004) that were made to fit the ICRP Publication 89 (ICRP, 2002) recommendations regarding organs weights. VIP-Man created by $\mathrm{Xu}(\mathrm{Xu}$ et al., 2000) and the Canine Anatomic Phantom designed by Padilla (Padilla et al., 2008). More details about the characteristics and availability of voxel phantoms can be found on the reviews by Lemosquet and Zaidi (Lemosquet et al., 2003; Zaidi and $\mathrm{Xu}, 2007)$.

The purpose of these multiple projects is to create anthromorphic phantoms as realistic as possible regarding the human anatomy. The phantoms had to match the human subject, not only in terms of the organ geometries and shapes, but also in regards of the different materials, densities and chemical composition to create correct organ weights and simulate realistic radiation interaction with matter. Lorin de la Grandmaison et al. studied the organ weights of 684 Caucasian adults (Lorin de la Grandmaison et al., 2001) taking into account victim's age, gender, weight, limb dimensions and Body Mass Index (BMI). The objective of "the visible man" project was to create a 3D voxel phantom using CT scan images (Jacob, 1999) and to create a numerical model that would represent the entire masculine community. 2D images are turned into 3D before the dosimetry computations (Xu et al., 2000). A similar project called "the virtual man" has been performed by the ORNL (Easterley et al., 1998).

Software like MABDOSE and MIRDOSE that allow carrying out dosimetry reports are based on mathematical models (Clairand et al., 2000). While radiation transport codes for Monte Carlo simulations like the MCNPX code, EGSnrc, Penelope and many others... are associated to voxelized phantoms to realise the dosimetry calculations.

Although such models have great anatomical realism, they continue to represent one particular morphology, and thus, should not be systematically used for all the human subjects. Moreover, it is clear that calculations accuracy is increased when personalized and realistic phantoms are used. Hence, additional phantom adjustment is required to further match a given human victim.

For all these reasons, we explored the possibility to use a tool of the Artificial Intelligence: the Case-Based Reasoning whose principles are presented in the next part of this paper.

\section{The principles of the CBR}

Kolodner created a full CBR-System called CYRUS (Kolodner, 1993). This system, which consisted of several cases and a memory, formed the fundament for a lot of following projects. Figure 1 shows the logic of a CBR-System in a 


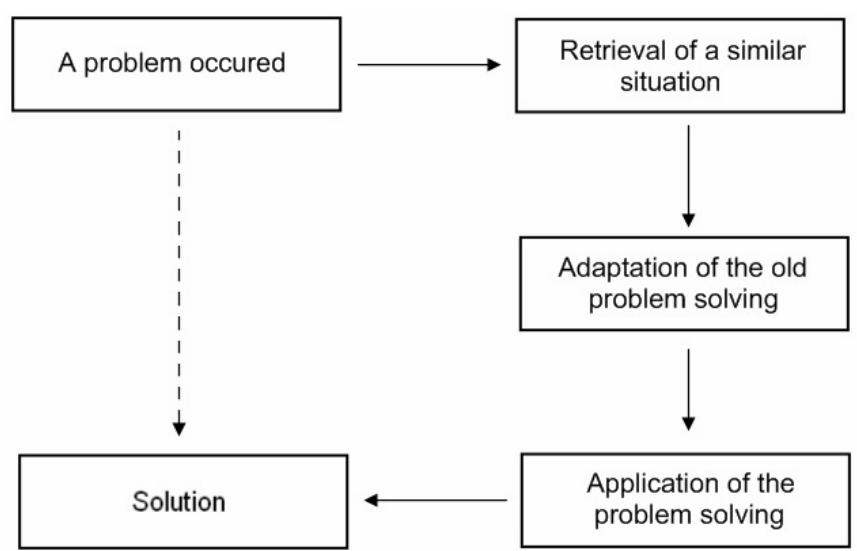

Figure 1 - Analogy square.

Carré d'analogie

simplified form (Mille et al., 1996). Generally the case description is organised as a problem and its known solution. These two parts constitute the structure of a case that is used in almost every CBR-System.

In a CBR-system there are always two types of cases, solved cases and new cases. An initial description of a problem defines a new case. After its resolution a new case becomes a solved case and is stored in the CBR database for future use. Only the section "problem description" is known in a new case whereas the two parts (the problem and its solution) are established in a solved case. The amount of solved cases forms the base of cases and is the heart of such a CBR-System because it represents the whole collection of information according to these known experiences. The CBR-system helps the experts to formalize a problem, memorize and adapt the known solutions which resemble the most to the problem, and finally and eventually store this new problem and its adapted solution to be able to remind it later.

Figure 2 represents the cycle of a whole CBR-System with its different processes. This cycle represents the main functions that such a system must satisfy. The central unit of the CBR-Cycle is the base of cases containing the previous cases i.e. the solved cases mentioned above.

The new case whose formalisation is similar to the description of a problem, is used to retrieve a case from the collection of the previous solved cases. A combination of the new case and the retrieved case defines a solved case via the process reuse $c f$. Figure 2 (Fusch et al., 2006). By a testing environment, the 


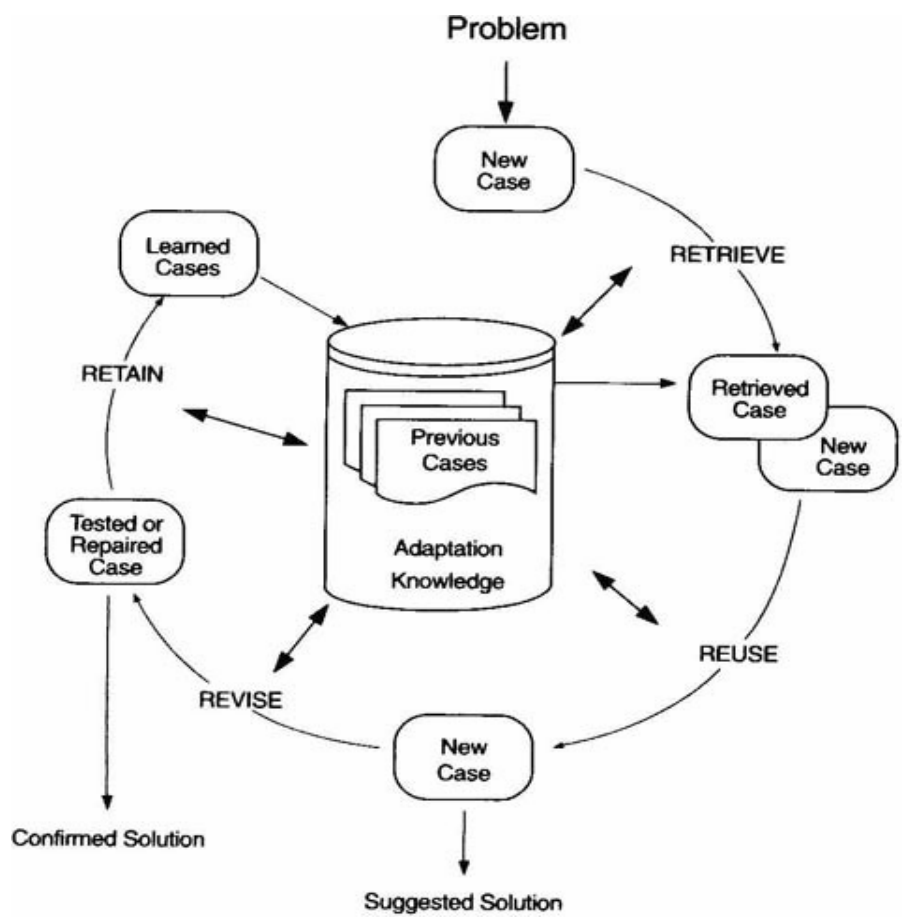

Figure 2 - The CBR-Cycle.

Cycle de fonctionnement du Raisonnement à Partir de Cas.

proposed solution will be revised and adapted for success (Aamodt, 2004). During the retain phase, useful experience is retained for future reuse which means that the base of cases is updated by a learned or a solved case. The CBR-principles are usually represented with four processes (retrieve, reuse, revise and retain). But it is mandatory to add another process that elaborates, at the beginning of the cycle, the new case from the problem (Mille, 1999) by formulating the comparison criteria. The case retrieve and the case reuse are two complex processes depending on the application. It is important to define the rules, vocabulary and ontology of the concerned domain in order to understand and characterize clearly the problem and also to be able to adapt correctly the solution of a retrieved case to the problem. Moreover, we can notice CBR systems have been implemented in very different fields (medicine, business, industrial maintenance, financial analysis and control) and very different tasks (classification, diagnosis, planning, design, interpretation, justification, decision help, document search, tool configuration and knowledge management) as shown in (Rasovska, 2006). The next part of this paper details the implementation we have done for applications in radiation protection. 


\section{The ReEPh platform}

This preliminary work aims to create an application that would optimize the radiation protection and dosimetry. It is focused on the lung counting problematic that deals with accidental incorporation of radionuclides and the estimation of the retained activity and its distribution in the human body. Each case is represented by a thorax phantom and its morphological descriptors and anatomic characteristics. This application is able to memorise a case as a solved case in the base of cases, to create a new case, to extract information from a DICOM-File (Digital Imaging Communication in Medicine), the international standard format used to store and exchange medical images, and to represent two similar cases graphically. The platform development is separated into two main parts: the first dealing with the case reasoning and the comparison criteria and the second is related to the similarity calculation basis and the associated confidence index. Moreover, phantom adaptation is previewed to improve the fit to the real victim.

At this stage of our work, the problem description, the information retrieval phase, and the retain phase have been implemented, but the adaptation phase has not been designed yet. Work is still on progress to define the best strategy and methodology to realize the morphology adaptation.

\subsection{The creation of the cases and the base}

The ReEPh database includes the list of phantoms to be used as models for the comparison with the victim and among which the most adapted one should be extracted for the dosimetry calculation. These models included the following structures: lungs, heart, liver, sternum, ribs, scapulae, spine, breasts and skin along with the chest wall itself.

One of the main objectives has been to determine the list of parameters that are necessary to describe and to establish the solution i.e. the comparison criteria to attribute the correct phantom, from the database, to the victim. Nevertheless, this list is not complete, and some descriptors may be of higher/lesser importance depending on the application. Practice and experience will allow the study of the pertinence of each descriptor. In this application, we have identified and included some general characteristics like age, size, weight, gender, smoker/non smoker. Some other ones, specific to the thorax region and the in vivo problematic, like organs volumes (cardiac, lung and thorax volumes) tissue composition (mainly fat/muscle proportion) and bones thickness (wrist diameter that can help in assessing the bone weight) along with external measurements like the chest/bust circumference. It is very interesting to notice that most of these parameters are present in the DICOM-file since a questionnaire is realised and such data are required and investigated for each victim ongoing any hospital care or treatment. 
Moreover, since some descriptors were considered to be more important than others as it is the case in in vivo monitoring, a weight was also added to each descriptor to stress its importance/unimportance. This weight will be very useful for the similarity calculation and the confidence index evaluation ( $c f$. next section). Nevertheless, it is very difficult to estimate those weights especially since they are totally dependant on the application. Indeed, when a dosimetry study is to be realised, the phantom choice must take into account the internal organs definition with greater importance when compared to external parameters. Whereas, in the case of in vivo measurements, particular parameters of chest wall thickness and lung volume have greater impact on the count and should thus have the highest importance.

On the other hand, some descriptors, particularly of a victim case, may be unknown, for example it is not always possible to measure the lung volume. Thus, a null weight was attributed to such descriptors to simulate the absence of information. However, since the ReEPh application aims to give a solution to the case, the higher the number of "informed" descriptors, the better the convergence to the "correct" solution. Consequently, the empty descriptors decrease the confidence index ( $c f$. next section).

As aforementioned there are always two types of cases, the new case and the solved cases. In this work we replace new case by victim case and solved case by model case so that the terms are clear for the experts of radiation protection. In a victim case the solution part is empty, because it is exactly what we want to determine to create a new model case. At the end, this part will contain the reference to the 3D phantom. The base of cases of our work will be formed by model cases. At the beginning only the cases of the known voxel phantoms will be memorised, but with the continuous use of the application the number of model cases memorised in the base of cases will increase. With the growing number of model cases there is statistically more chance to find one or several model cases that are of higher similarity to the victim case.

\subsection{The retrieval phase}

The main purpose of the ReEPh platform is to retrieve the most similar phantom(s) of one victim regardless of the available number of descriptors. Thus, the experts need to have a confidence index with the solution retrieved by the ReEPh platform along with the similarity index. In this part, we present the method used for the assessment of the similarity between two cases and the confidence index as calculated by the ReEPh platform. 
Here are the notations used:

- $\quad i$ is the index of the victim case;

- $j$ is the index of the model case with which $i$ is compared;

- $n$ is the total number of descriptors of each model case. This number may change with the study of the AFNOR norms ( $c f$. the previous section). For all the model cases, all the descriptors are known whereas some descriptors of the victim case may not have any value;

- $\lambda_{k}$ is the weight of the descriptor $k$ stressing its importance. Indeed, some characteristics are more important than the others. The more important the descriptor $k$ is, the higher the value of $\lambda_{k}$ is;

- $\delta_{k}^{i}$ indicates whether the value of the $k$ descriptor of the victim case is known or not since some descriptor values may be missing. When the value of the descriptor $k$ of $i$ is missing $\delta_{k}^{i}=0$, otherwise $\delta_{k}^{i}=1$;

- $\quad D_{k}$ is the maximum known value descriptor $k$ can take; it is not the maximum value of the stored phantoms. For example, we considered someone's size can vary from 0 to 230 centimetres and his age from 0 to 110 ;

- $d_{k}$ is the minimum known value of $k$;

$-\Delta_{k}=D_{k}-d_{k}$

- $d_{k}^{i}$ is the minimum known value of the descriptor $k$ of the victim case $i$;

- $d_{k}^{j}$ is the minimum known value of the descriptor $k$ of the model case $j$;

- $S_{i, j}$ is the similarity value between the victim case $i$ and the model case $j$;

- $I_{i}$ is the confidence index of the victim case $i$. We can notice that the value of $I_{i}$ does not depend on the values of the model case descriptors. Indeed, all the descriptors of each model case are known. The uncertainty depends only on the victim case.

For this first version of the ReEPh platform, we chose to use a classical algorithm for the similarity calculation, the $K-n n$ Algorithm (K-nearer neighbours Algorithm) which appears to be the best suited to our problem since a weight can be applied to the descriptor values. The weight values, affected to each parameter, will also be studied in a future step, since this weight depends on the descriptors importance and the dosimetry application. Moreover, the ReEPh platform is designed to retrieve a set of cases, and not only one to give the user a wider choice of phantoms and the possibility to decide upon his experience and interest. Indeed, it is possible to graphically compare the victim case to the model cases the ReEPh platform sorts according to the similarity values and some users may find the use of the second fit more appropriate for their particular application/situation. We have also introduced in the Knn Algorithm the fact that the values of some descriptors may be missing by adding the $\delta_{k}^{i}$ index in the similarity calculation. Consequently, we obtained formula (1) for estimating the similarity between the 
cases $i$ and $j$ :

$$
S_{i, j}=\frac{\sum_{k=1}^{n} \delta_{k}^{i} \lambda_{k}\left[\frac{\Delta k-\left|d_{k}^{i}-d_{k}^{j}\right|}{\Delta k}\right]}{\sum_{k=1}^{n} \lambda_{k} \delta_{k}^{i}}
$$

with formula (1), we only take into account the known values of the victim case. We can also see that each difference is first converted in values between 0 and 1 (with the part $\frac{\Delta k-\left|d_{k}^{i}-d_{k}^{j}\right|}{\Delta k}$ of the formula (1)). Then, the weight is applied. The similarity value is always between 0 and 1 . The more the cases $i$ and $j$ are similar, according to the known values, the closer this value is to 1 .

Nevertheless, the confidence index must be taken into account. Indeed, if the victim's age is the only known criteria, the similarity value calculated are totally insignificant. So the confidence index takes into account the number of known values according formula (2):

$$
I_{i}=\frac{\sum_{k=1}^{n} \delta_{k}^{i} \lambda_{k}}{\sum_{k=1}^{n} \lambda_{k}}
$$

Thus, the more values we know, the higher the confidence index is.

The next part of this paper presents the way the ReEPh platform is working through an example.

\section{The results of the ReEPh platform through an example}

The ReEPh platform allows the experts to choose the most adapted phantom thanks to the computations of the similarity and confidence indices and also an original interface representing the graphical comparison.

Table I shows the descriptor values of a victim case and the ones of two model cases representing two phantoms stored in the base of cases. The first phantom represents the thorax of a woman which measurements correspond to the clothing 
TABLE I

The victim, the first and the second phantom characteristics. Caractéristiques de la victime et des deux fantômes.

\begin{tabular}{lllll}
\hline \multicolumn{1}{c}{ Descriptor designation } & Descriptor weights & Phantom “85A" & Phantom “120F" & Victim \\
\hline age $($ years $)$ & 2 & 43 & 43 & 20.4 \\
\hline size $(\mathrm{cm})$ & 3 & 167 & 182 & 162 \\
\hline weight $(\mathrm{kg})$ & 3 & 50.42 & 94.72 & 46 \\
\hline gender $(\mathrm{M} / \mathrm{F})$ & 2 & $\mathrm{~F}$ & $\mathrm{~F}$ & $\mathrm{~F}$ \\
\hline smoker $(\mathrm{O} / \mathrm{N})$ & 1 & $\mathrm{~N}$ & $\mathrm{~N}$ & $\mathrm{~N}$ \\
\hline thorax volume $(\mathrm{l})$ & 1 & 13.72 & 33.40 & \\
\hline lung volume $(\mathrm{l})$ & 1 & 2.30 & 2.99 & \\
\hline extra-thoracic thickness $(\mathrm{cm})$ & 1 & 2.1 & 11.6 & \\
\hline fat-muscle proportion $\left(\mathrm{kg} / \mathrm{m}^{2}\right)$ & 1 & 18.08 & 28.60 & 68.9 \\
under bust circumference $(\mathrm{cm})$ & 4 & 71 & 105 & 82.1 \\
chest circumference $(\mathrm{cm})$ & 4 & 84 & 128 & \\
wrist diameter $(\mathrm{cm})$ & 0 & N/A & N/A & \\
cardiac volume $(\mathrm{l})$ & 1 & 0.59 & 0.77 & Caucasian \\
\hline origin & 1 & Caucasian & Caucasian \\
similarity index & & $\mathbf{0 . 7 6 5 5}$ & $\mathbf{0 . 5 7 3 2}$ & \\
confidence index & & $\mathbf{0 . 8}$ & $\mathbf{0 . 8}$ & \\
\hline
\end{tabular}

norm " $85 \mathrm{~A}$ " and the second one the thorax of a " $120 \mathrm{~F}$ " subject. The weights have been affected taking into account the importance of each measure and the concerned area: the thorax. In the case of in vivo counting, it is known that chest wall thickness, computed from the chest circumference differences under/over breasts, and lungs volume are the most important values. Hence, their associated weights have been put to the highest value: 4 . Moreover, in this example, only the external measures of the victim are known, thus the weights associated to the internal volumes have been put to 1 . Furthermore, the weight values depend on the exposed area and the characteristics of the dosimetry report/application to be done. Those values depend also on the phantoms, the accuracy of the descriptor values and the expert experience. Indeed, if an expert considers the information "smoker/non-smoker" is very important, the phantoms of smokers would be clearly distinguished from the ones of non-smokers, and the weight should be put to the highest value. Other experts may attribute other values.

We compared the results obtained with the closest phantom to the ones obtained with the further apart one. Since the victim case available descriptors and the associated weights were constant, the $\mathrm{CI}$ is the same for both phantoms and was found to be equal to 0.8. This confidence index, equivalent to an incertitude calculation ( $c f$. Sect. 4.3), suggests that the SI obtained can be trusted. The SI 
computed for the first phantom was equal to 0.7655 , meaning that the considered victim and the base of cases phantom correspond up to $76 \%$ considering the available descriptors. This result has been confirmed since the external measures of this victim correspond to the "85A" subject typically in regards of the chest and under bust circumferences. The least close phantom corresponds to the "120F" clothing norm and its SI is equal to 0.5732 . Nevertheless, it is quite difficult to make a choice with only two relative values like the SI and the CI and personal experience and practice are required. In order to complete this retrieve phase, another tool is available on the ReEPh platform: the ReEPh GUI (Graphical User's Interface) that allows users to compare all the model cases to the victim case graphically. Figure 3 shows the graphical representation of the victim case (the darker area) and the model case (the lighter area). Each axis represents one descriptor of the case. On each axis, the value of the victim case descriptor and the value of the same descriptor relative to the selected model case are reported if known. If the phantom and the victim characteristics are the same, the areas will be merged. Thus, the better the areas are merged, the more similar the phantom is to the victim. Considering the first phantom, the known characteristic of the victim reasonably concordat, and thus most of the points on axis are merged, whereas they are very different on the graph which compares the victim to the "120F" phantom. As a matter of fact, the ReEPh GUI clearly shows that the cases are very similar if only the known values are taken into account, but it has to be put into perspective: the confidence index is an average. Thus, the "areas" are not merged at all in both cases since some of the victim characteristics are not known. We chose not to take into account the weights for this GUI so that the expert does not forget some information is unknown. This point is under reflexion: on one hand, not to consider some information has some risks while taking into account the weights on such a graph may minimize the differences, on the other hand, the expert will probably have to fulfil an important reflexion on the importance and pertinence of each of the characteristics while using such a tool. Nevertheless, it is easier to see, with this GUI, how similar the cases are along with the numerical values obtained for the SI and CI. It is also very simple to find out what the critical characteristics and differences are and to have an idea of the distance between two cases. As mentioned above, the ReEPh project retrieves a set of model cases. The numerical values of all the descriptors of the stored phantoms can also be retrieved and since they are presented to the expert when he (or she) compares one victim to one phantom with the graphical comparison interface.

\section{Conclusion and prospects}

The ReEPh project proves it is possible to use the CBR principles in radiation protection as a tool to help the physician to choose the most adapted phantom and 
FEASIBILITY STUDY OF A NEW PLATFORM
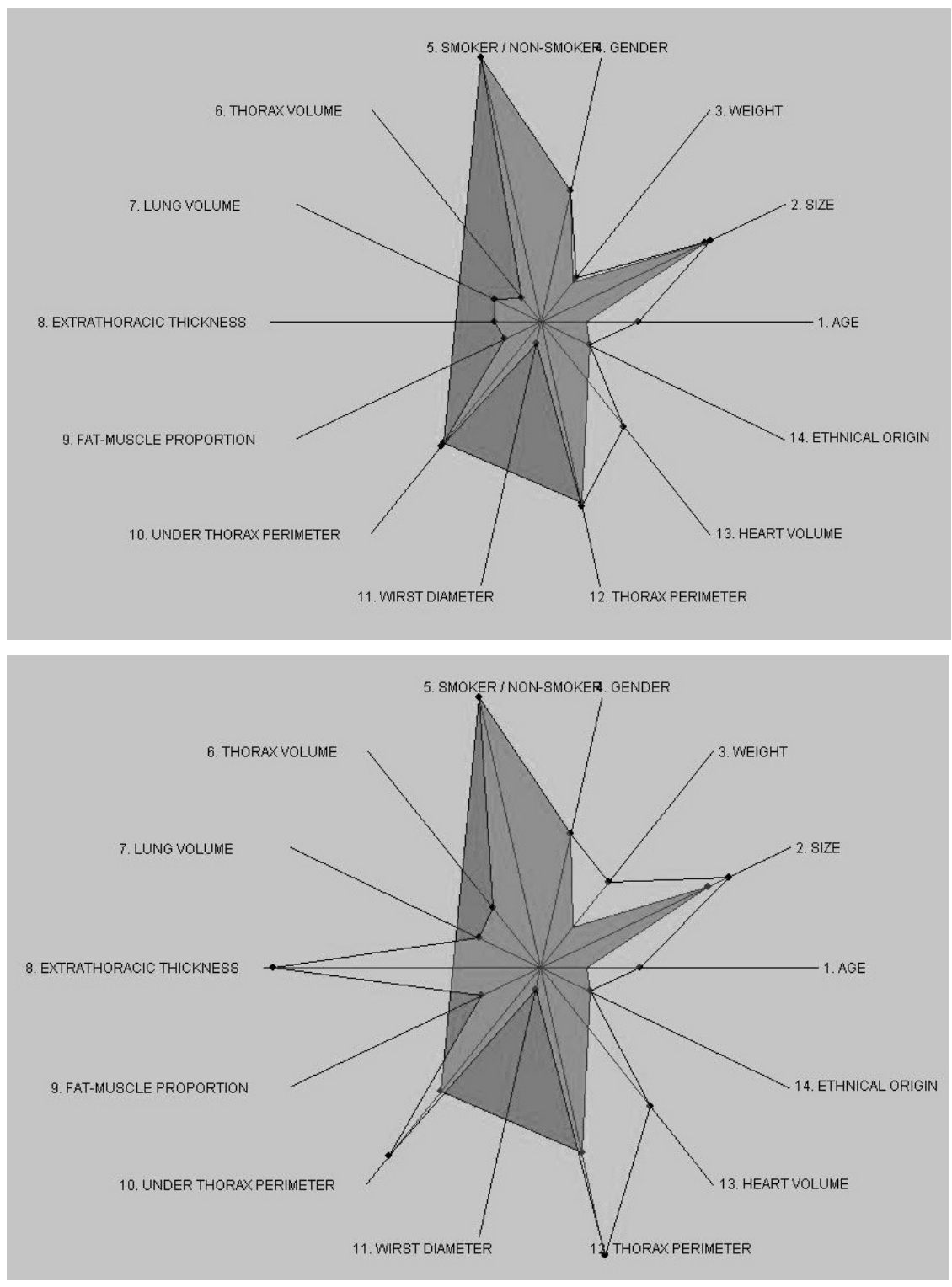

Figure 3 - The ReEPh graphical comparison of the victim case with respectively phantoms " $85 A$ " and "120F".

Graphiques de comparaison de l'application ReEPh de la victime avec le fantôme « $85 \mathrm{~A}$ » et de la victime avec le fantôme « $120 \mathrm{~F} »$. 
the most similar one when compared to the victim starting from a given set or database. For this first version, the ReEPh platform retrieves, stores and compares existing phantoms to a victim. A victim, as a stored phantom, is described through a set of parameters and descriptors. During the retrieve and comparison phase, a similarity index is calculated according to Knn algorithm that was however adapted to take into account a parameters importance differentiation that was done by a differential weight attribution. This platform integrates the constraints found in real cases: some descriptors may be unknown while others could have higher/lesser importance. A graphic interface permits to compare the victim's characteristics and the ones of the most similar phantoms (given in a case base) to the victim. A confidence index is also calculated in order to take into account the uncertainty implied by the possible missing characteristics of the victim.

The full extraction of all descriptors (i.e. internal organ volumes) from a DICOM-file is soon to be implemented. Indeed, the internal organs volumes can be calculated from the DICOM-file once the radiologist has delimited by manual segmentation the organs. This process will enable the adding of more phantoms, and sometimes to help the description of a victim if any DICOM-files of this victim exist. Further work will determine precisely, in association with the radiation protection experts, the importance of each weight. Nevertheless, the value of this weight also depends on the capacity to adapt a phantom according to one particular descriptor. Indeed, the most similar phantom to the victim is not always the easiest one to modify to attend the correct and exact values. For example, in some cases of a female victim with rather small breasts, it can be easier to modify a male model by adding the breasts rather than starting from an existing female model with lesser resemblance but higher similarity index if the "sex" index is associated to a significantly high weight.

Consequently, in the future, we may not deal with the similarity, but with the adaptation easiness. At this stage of our work, the problem description, the retrieve phase, and the retain phase have been implemented, but the adaptation phase has not been designed yet. This will be the next step of our research in this domain. This new aspect requires introducing more information specific to the planned usage: a real ontology of the phantoms used by radiation protection experts will be necessary.

Acknowledgments. The authors would like to acknowledge the French Society for Radiation Protection (SFRP) for providing financial support for this preliminary work. 


\section{REFERENCES}

Aamodt A. (2004) Knowledge-Intensive Case-Based Reasoning and Sustained Learning, in Proceedings of the 9th European Conference on Artificial Intelligence, ECCBR'04, Lecture Notes in Artificial Intelligence, Springer, pp. 1-15.

Broggio D., Zhang B., de Carlan L., Desbée A., Lamart S., le Guen B., Bailloeuil C., Franck D. (2009) Analytical and Monte Carlo assessment of activity and local dose after a wound contamination by activation products, Health Phys. 96, 155-163.

Caon M., Bibbo G., Pattison J. (1999) An EGS-4ready tomographic computational model of 14-yearold female torso for calculating organ doses from CT examinations, Phys. Med. Biol. 44, 2213-2225.

Clairand I. (1999) Développement de nouveaux modèles physiques dédiés à la dosimétrie interne par l'utilisation du code de Monte Carlo EGS, Thèse de l'Université Paul Sabatier, Toulouse.

Clairand I., Bouchet L.G., Ricard M., Durigon M., Di Paola M., Aubert B. (2000) Improvement of internal dose calculations using mathematical models of different adult heights, Phys. Med. Biol. 45, 2771-2785.

Clairand I., Huet C., Trompier F., Bottollier-Depois J.-F. (2008) Physical dosimetric reconstruction of a radiological accident due to gammagraphy equipment that occurred in Dakar and Abidjan in summer 2006, Rad. Measur. 43, 698-703.

Cristy M., Eckerman K.F. (1987) Specific absorbed fractions of energy at various ages from internal photons sources, ORNL Report/TM-8381, Oak Ridge, Oak Ridge National Laboratory.

de Carlan L., Aubineau-Lanièce I., Lemosquet A., Borissov N., Jourdain J.R., Jeanbourquin D., Le Guen B., Franck D. (2003) Application of new imaging and calculation techniques to activity and dose assessment in the case of a 106Ru contaminated wound, Rad. Prot. Dosim. 105, 219-223.

Dimbylow P.J. (1998) Induced current densities from low-frequency magnetic fields in a $2 \mathrm{~mm}$ resolution, anatomically realistic model of the body, Phys. Med. Biol. 43, 221-230.

Easterley C.E., Allgood G., Eckerman K.F., Knee B., Maston M., MacNeilly G., Munro J., Munro N., Toerite R., Van Hoy B. (1998) The virtual human: a diagnostic tool for human studies and health effects in the 21st century, SPIE Int. Soc. Opt. Engineer. 3253, 150-154.

Fusch B., Lieber J., Mille A., Napoli A. (2006) Une première formalisation de la phase d'élaboration du raisonnement à partir de cas, in Actes du $14^{e}$ atelier du raisonnement à partir de cas, Besançon, France.

Huet C., Lemosquet A., Clairand I., Rioual J.B., Franck D., de Carlan L., Aubineau-Lanièce I., Bottollier-Depois J.F. (2009) SESAME: a software tool for the numerical dosimetric reconstruction of radiological accidents involving external sources and its application to the accident in Chile in December 2005, Health Phys. 96, 76-83.

ICRP Publication 89 (2002) Basic anatomical and physiological data for use in radiological protection, Ann. ICRP 32(3-4).

ICRU (1992) Phantoms and Computational Models in Therapy, Diagnosis and Protection, in International Commission on Radiation Units and Measurements, Report 48.

Jacob S.W. (1999) The complete visible man: the complete high resolution male and female anatomical datasets from the visible human project, J. Am. Med. Assoc. 281, 765.

Kolodner J. (1993) Case-Based Reasoning, Morgan Kaufmann Publishers.

Kramer R., Zankl M., Williams G., Dexter G. (1982) The calculation of dose from external photon exposures using reference human phantoms and Monte Carlo methods. Part I: the male (Adam) and female (Eva) adult mathematical phantoms, Report GSF-Bericht S-885, München, GSF. 
Kramer R., Vieira J.W., Khoury H.J., Lima F.R.A., Fülle D. (2003) All About MAX: A Male Adult VoXel phantom for Monte Carlo Calculations in Radiation Protection Dosimetry, Phys. Med. Biol. 48, 1239-1269.

Kramer R., Khoury H.J., Vieira J.W., Loureiro E.C.M., Lima V.J.M., Lima F.R.A., Hoff G. (2004) All about FAX: a Female Adult voXel phantom for Monte Carlo calculation in radiation protection dosimetry, Phys. Med. Biol. 49, 5203-5216.

Lemosquet A., de Carlan L., Clairand I. (2003) Voxel anthropomorphics phantoms: review of models used for inionizing radiation protection, Radioprotection 38, 509-528

Lorin de la Grandmaison G., Clairand I., Durigon M. (2001) Organ weight in 684 adult autopsies: new tables for a Caucasoid population, Forensic. Sci. Intern. 119, 149-154.

Makovicka L., Vasseur A., Sauget M., Martin E., Gschwind R., Henriet J., Salomon M. (2009) The future of new calculation concepts in dosimetry based on the Monte Carlo methods, Radioprotection 44, 77-88.

Mille A. (1999) Tutorial CBR : Etat de l'art de raisonnement à partir de cas, Plate-forme AFIA'99, Palaiseau, France.

Mille A., Fuchs B., Herbeaux O. (1996) A unifying Framework for Adaptation in Case-Based Reasoning, in Workshop on Adaptation in Case-Based Reasoning, ECAI'96, Budapest, Hungary, pp. 22-28.

Padilla L., Lee C., Milner R., Shahlaee A., Bolch W.E. (2008) Canine Anatomic Phantom for Preclinical Dosimetry in Internal Emitter Therapy, J. Nucl. Med. 49, 446-452.

Rasovska I. (2006) Contribution à une méthode de capitalisation des connaissances basée sur le raisonnement à partir de cas : Application au diagnostic dans une plateforme d'e-maintenance, Thèse de l'Université de Franche-Comté, Besançon, France

Snyder W.S., Ford M.R., Warner G.G. (1978) Estimates of absorbed fractions for mono-energetic photons sources uniformy distributed in various organs of a heterogeneous phantom, MIRD pamphlet number 5 revised, New York, The Society of Nuclear Medicine.

Tanaka G.I., Kawamura H., Nakahara Y. (1979) Reference Japanese man-I. Mass of organs and other characteristics of normal Japanese, Health Phys. 36, 333-346.

Xu X.G., Chao T.C., Bozkurt A. (2000) VIP MAN, an imaged-based wholebody adult male model constructed from color photographs of the visible human project for multi-particle Monte Carlo calculations, Health Phys. 78, 476-486.

Zaidi H., Xu X.G. (2007) Computational anthropomorphic models of the human anatomy: the path to realistic Monte Carlo modelling in radiological sciences, Annu. Rev. Biomed. Eng. 9, 471-500.

Zankl M., Viet R., Williams G., Schneider K., Fendel H., Petoussi N., Drexler G. (1988) The construction of computer tomographic phantoms and their application in radiology and radiation protection, Rad. Environm. Biophys. 27, 153-164.

Zankl M., Panzer W., Petoussi-Hens N., Drexler G. (1995) Organ doses for children from computed tomographic examinations, Rad. Prot. Dosim. 57, 393-396.

Zankl M., Wittmann A. (2001) The adult male voxel model 'Golem' segmented from whole-body CT patient data, Rad. Environm. Biophys. 40, 153-162.

Zubal I.G., Harrell C.R., Smith E.O., Rattner Z., Gindi G., Hoffer P.B. (1994) Computerized three dimensional segmented human anatomy, Med. Phys. 21, 299-302. 